\title{
The whole transcriptome effects of the PPARa agonist fenofibrate on livers of hepatocyte humanized mice
}

\author{
Montserrat A. de la Rosa Rodriguez', Go Sugahara², Guido J. E. J. Hooiveld', Yuji Ishida ${ }^{2,3}$, Chise Tateno 2,3
} and Sander Kersten ${ }^{1 *}$ (D)

\begin{abstract}
Background: The role of PPARa in gene regulation in mouse liver is well characterized. However, less is known about the role of PPARa in human liver. The aim of the present study was to better characterize the impact of PPARa activation on gene regulation in human liver. To that end, chimeric mice containing hepatocyte humanized livers were given an oral dose of $300 \mathrm{mg} / \mathrm{kg}$ fenofibrate daily for 4 days. Livers were collected and analyzed by hematoxilin and eosin staining, QPCR, and transcriptomics. Transcriptomics data were compared with existing datasets on PPARa activation in normal mouse liver, human primary hepatocytes, and human precision cut liver slices.
\end{abstract}

Results: Of the different human liver models, the gene expression profile of hepatocyte humanized livers most closely resembled actual human liver. In the hepatocyte humanized mouse livers, the human hepatocytes exhibited excessive lipid accumulation. Fenofibrate increased the size of the mouse but not human hepatocytes, and tended to reduce steatosis in the human hepatocytes. Quantitative PCR indicated that induction of PPARa targets by fenofibrate was less pronounced in the human hepatocytes than in the residual mouse hepatocytes. Transcriptomics analysis indicated that, after filtering, a total of 282 genes was significantly different between fenofibrate- and control-treated mice $(P<0.01) .123$ genes were significantly lower and 159 genes significantly higher in the fenofibrate-treated mice, including many established PPARa targets such as FABP1, HADHB, HADHA, VNN1, PLIN2, ACADVL and HMGCS2. According to gene set enrichment analysis, fenofibrate upregulated interferon/cytokine signaling-related pathways in hepatocyte humanized liver, but downregulated these pathways in normal mouse liver. Also, fenofibrate downregulated pathways related to DNA synthesis in hepatocyte humanized liver but not in normal mouse liver.

Conclusion: The results support the major role of PPARa in regulating hepatic lipid metabolism, and underscore the more modest effect of PPARa activation on gene regulation in human liver compared to mouse liver. The data suggest that PPARa may have a suppressive effect on DNA synthesis in human liver, and a stimulatory effect on interferon/ cytokine signalling.

Keywords: Hepatocyte humanized mice, Fenofibrate, PPARa, Transcriptomics, Lipid metabolism, DNA synthesis

\section{Background}

The Peroxisome Proliferator Activated Receptors (PPARs) are a group of nuclear receptors involved in the transcriptional regulation of a variety of biological processes, including lipid metabolism and inflammation [1-3]. PPARs regulate gene expression by acting as

\footnotetext{
* Correspondence: sander.kersten@wur.nl

${ }^{1}$ Nutrition, Metabolism and Genomics group, Division of Human Nutrition and Health, Wageningen University, Stippeneng 4, 6708, WE, Wageningen, The Netherlands

Full list of author information is available at the end of the article
}

ligand-activated transcription factors. PPARs interact with DNA as part of a heterodimeric complex with the retinoid X receptor RXR [4-6]. The ligands for PPARs cover a broad range of synthetic and endogenous compounds ranging from environmental contaminants to specific drug classes, fatty acids, eicosanoids, and other lipid species [7]. Three different PPAR subtypes exist in mammals: PPAR $\alpha, \operatorname{PPAR} \beta / \delta$, and PPAR $\gamma$, each with a distinct tissue expression profile and set of functions.

(c) The Author(s). 2018 Open Access This article is distributed under the terms of the Creative Commons Attribution 4.0 International License (http://creativecommons.org/licenses/by/4.0/), which permits unrestricted use, distribution, and reproduction in any medium, provided you give appropriate credit to the original author(s) and the source, provide a link to the Creative Commons license, and indicate if changes were made. The Creative Commons Public Domain Dedication waiver (http://creativecommons.org/publicdomain/zero/1.0/) applies to the data made available in this article, unless otherwise stated. 
PPAR $\alpha$ is expressed in several tissues, particularly in liver, kidney, heart, skeletal muscle and intestine [8,9]. Studies in mice using whole-body or liver-specific PPAR $\alpha-/-$ mice have shown that PPAR $\alpha$ is the master regulator of lipid metabolism in the liver during fasting [10-12]. Specifically, fasted PPAR $\alpha-/-$ mice suffer from a host of metabolic abnormalities including hypoglycemia, hypoketonemia, elevated plasma non-esterified fatty acids, and a fatty liver. These metabolic defects are rooted in defective transcription of hundreds of genes involved in numerous metabolic pathways covering nearly every aspect of hepatic lipid metabolism [13].

Besides its role as key transcriptional regulator of lipid metabolism during fasting, PPAR $\alpha$ is mainly known as the receptor for a diverse group of compounds known as peroxisome proliferators $[14,15]$. The group of peroxisome proliferators include plasticizers, insecticides, herbicides, surfactants, organic solvents, and hypolipidemic fibrate drugs [16]. Safety concerns have been raised about these compounds due to their ability to promote hepatocarcinogenesis and the proliferation of peroxisomes in rodent species $[17,18]$. Studies using human liver model systems have largely allayed these concerns by failing to find supportive evidence for a proliferative and pro-carcinogenic effect of PPAR $\alpha$ ligands in human cells [19].

Whereas the effect of PPAR $\alpha$ ligands on cell and peroxisome proliferation is clearly distinct between rodent and human liver cells, the effect of PPAR $\alpha$ ligands on the expression of genes involved in lipid metabolism is generally well conserved between the different species. Indeed, numerous genes connected to lipid metabolism are commonly induced by PPAR $\alpha$ ligands in mouse and human hepatocytes, including prototypical PPAR $\alpha$ targets such as CPT1A, ACOX1, FABP1, and HMGCS2 [20]. A recent review on PPAR $\alpha$ summarizes the conclusions that can be reached from the use of human liver model systems [19]. In particular, it was concluded that PPAR $\alpha$ in human liver is able to effectively induce the expression of genes involved in numerous lipid metabolic pathways. In addition, similar to what is observed in mouse liver, PPAR $\alpha$ activation in human liver causes the down-regulation of a large number of genes involved in various immunity-related pathways $[19,21]$.

The specific model systems used to study PPAR $\alpha$ in human liver vary from hepatoma cell lines such as HepG2 to human primary hepatocytes [20, 22-24], human precision cut liver slices [21], and mice expressing human PPAR $\alpha[25,26]$. Each of these model systems have their specific advantages and disadvantages. An alternative model consist of chimeric mice carrying human liver cells. These mice are generated by transplanting human hepatocytes into albumin enhancer-driven urokinase-type plasminogen activator transgenic/severe combined immunodeficiency (uPA/SCID) mice, leading to replacement of the host hepatocytes at a repopulation rate exceeding $70 \%[27,28]$. An important advantage of the hepatocyte humanized livers is that the hepatocytes still replicate, in contrast to cultured human primary hepatocytes or liver slices. Recently, we used these PXB mice to study the in vivo effect of PPAR $\alpha$ activation using fenofibrate on peroxisome proliferation and the growth of human hepatocytes in mice, leading to the conclusion that rodent data on PPAR $\alpha$-induced hepatocarcinogenesis cannot be accurately extrapolated to humans [2]. Here, we performed transcriptomics analysis on the effect of fenofibrate in chimeric mice with hepatocyte humanized livers and compared the results with other relevant transcriptomics datasets.

\section{Results}

First, we compared the whole genome expression profile of human liver biopsies with the whole genome expression profile of hepatocyte humanized mouse livers, human primary hepatocytes, and human precision-cut liver slices. Scatter plot analysis of normalized expression values revealed that a substantial number of genes that showed expression in human liver tissue were minimally (or not) expressed in hepatocyte humanized livers (Fig 1a). Pathway analysis on this differentially expressed set of genes showed overrepresentation of genes involved in focal adhesion, complement and coagulation, and various immune-related pathways (Fig. 1b), which likely reflects the repopulation of the transplanted human hepatocytes in an immuno-deficient host. Interestingly, for highly expressed genes, hepatocyte humanized livers more closely resembled actual human liver tissue as compared to human primary hepatocytes and human precision-cut liver slices, as reflected by the smaller scatter at the high expression range.

Besides the scatter analysis, we utilized principle component analysis to compare the transcriptome of human liver of different types of subjects (normal, healthy obese, steatosis, and NASH) with hepatocyte humanized mouse liver and other liver models, including human primary hepatocytes and human liver slices (Fig. 1c). The results clearly indicate that the gene expression profiles of hepatocyte humanized liver samples are much closer to human liver as compared to human primary hepatocytes and human liver slices. Interestingly, no clear separation between the different groups of human subjects was found, suggesting that the different liver histological phenotypes do not have a distinctive gene expression profile.

As a final validation of the model, mRNA expression levels of PPAR $\alpha$ in hepatocyte humanized livers were similar to the levels measured in human liver biopsies (Fig. 2a). These data support the notion that hepatocyte humanized livers are a suitable model for human liver, with some restrictions. 


\section{a} hepatocyte humanized mouse liver human precision cut liver slices human primary hepatocytes

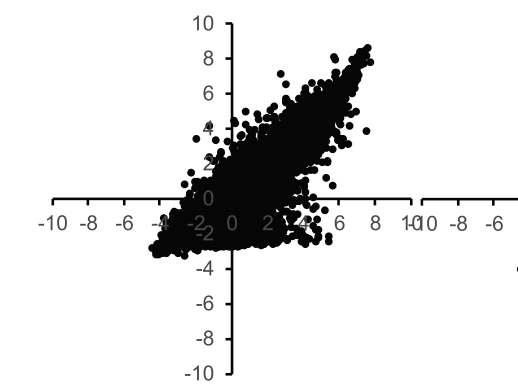

b

WikiPathways

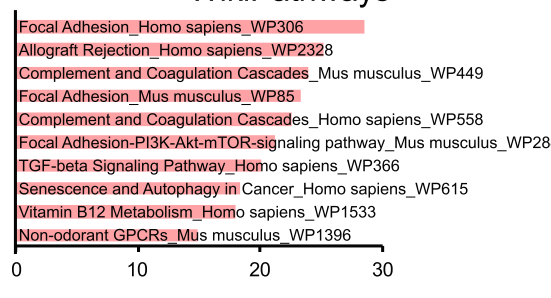

\section{KEGG}

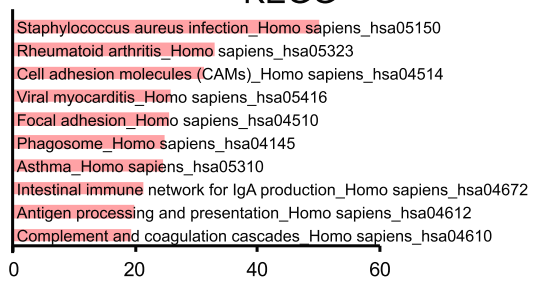

20

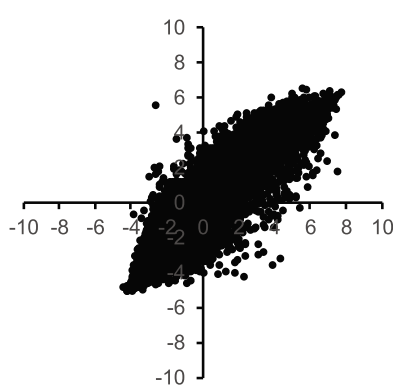

C

- human healthy obese liver - humanized mouse liver - human liver slices $\quad \bullet$ human NASH liver - human primary hepatocytes $\bullet$ human steatotic liver o normal human liver

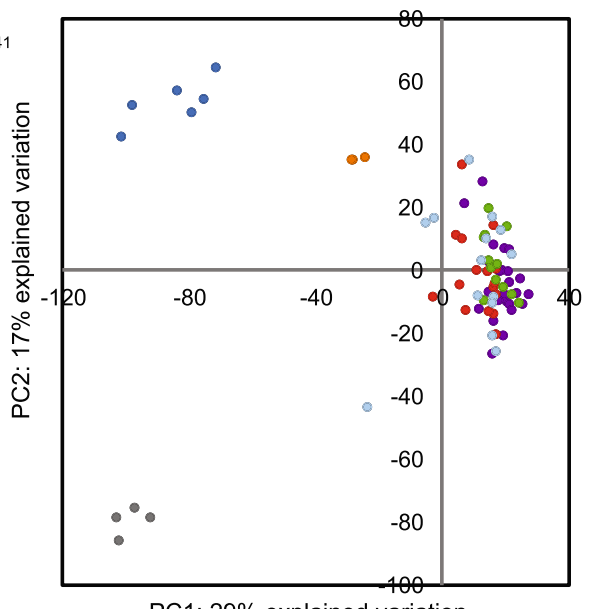

PC1: $29 \%$ explained variation

Fig. 1 Comparative transcriptomics analysis of different human liver model systems. Transcriptomics was carried out on human liver biopsies (GSE48452) [55], hepatocyte humanized livers, primary human hepatocytes (GSE76148) [24], and human precision-cut liver slices (GSE17251) [21]. a Scatter plot analysis of normalized expression values comparing the whole genome expression profile of the human liver biopsies ( $\mathrm{x}$-axis) with the whole genome expression profile of the hepatocyte humanized livers (left panel), human precision-cut liver slices (middle panel), and human primary hepatocytes (right panel) (all y-axis). b Genes that were expressed at much higher levels in human liver biopsies than in hepatocyte humanized livers ( $\Delta^{2} \log [$ normalized mean expression value] > 3) were imported into the Enrichr tool (http://amp.pharm.mssm.edu/Enrichr/ index.html) [31, 32]. The 10 pathways with the highest combined score are shown. c Principle component analysis was performed to compare the transcriptome of human liver of different types of subjects (normal, healthy obese, steatosis, and NASH) with hepatocyte humanized mouse liver and other liver models, including human primary hepatocytes and human liver slices

To study the effect of PPAR $\alpha$ activation on gene expression in hepatocyte humanized livers, chimeric mice with hepatocyte humanized livers were given fenofibrate or vehicle at a daily oral dose of $300 \mathrm{mg} / \mathrm{kg}$ for 4 days. Fenofibrate has a similar affinity for mouse and human PPARa [29]. Fenofibrate did not affect bodyweight or liver weight (Fig. 2b). Also, blood albumin (Fig. 2c), as well as plasma glucose, triglycerides and cholesterol levels were not significantly different between the fenofibrate and control-treated mice (Fig. 2d). Histological examination of the H\&E-stained livers showed clearly distinctive clusters of human and mouse hepatocytes. Human hepatocytes showed a light eosin staining while mouse hepatocytes were highly eosinophilic (Fig. 2e). In contrast to the mouse hepatocytes, the human hepatocytes exhibited excessive lipid accumulation (micro- and macrosteatosis), as previously demonstrated [30]. In agreement with our previous study [2], fenofibrate increased the size of the mouse hepatocytes but did not affect the morphology of the human hepatocytes. A tendency toward reduced steatosis by fenofibrate was observed in the sections of the liver populated by human hepatocytes (Fig. 2e).

To determine whether fenofibrate treatment stimulated PPAR $\alpha$-dependent gene regulation in the mouse and human hepatocytes, we measured the expression of mouse and human PPAR $\alpha$ target genes by qPCR in whole liver cDNA using species-specific primers. 

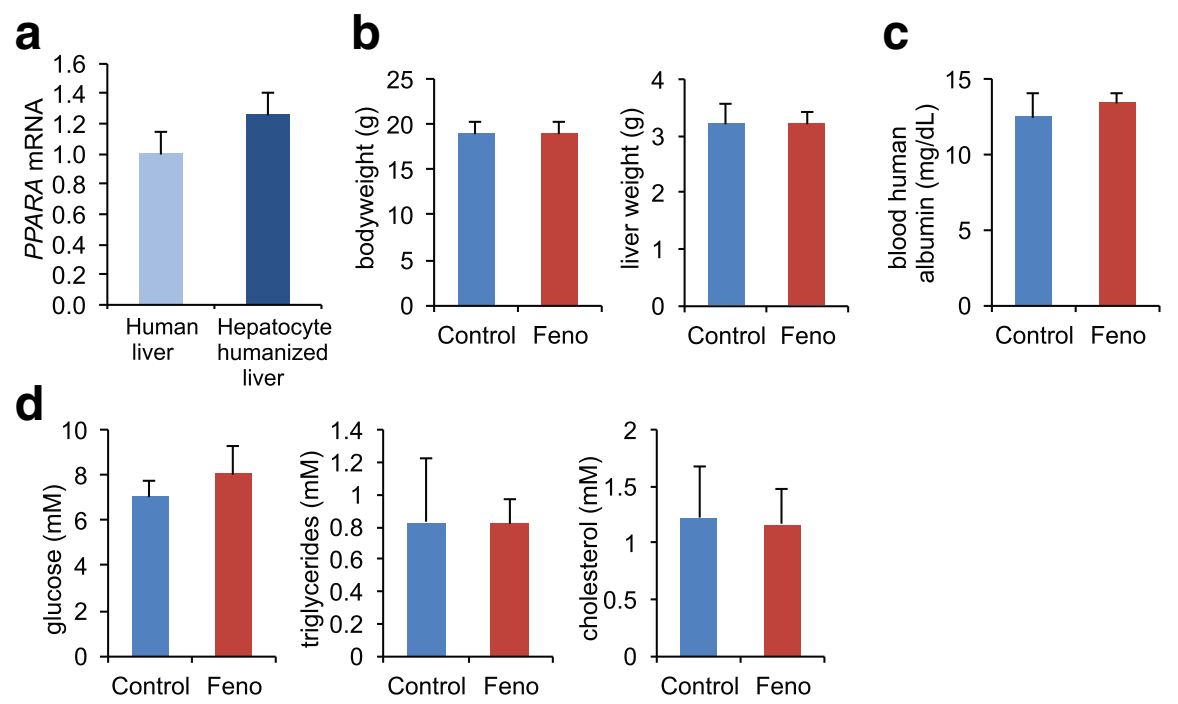

\section{e}

\section{Control}
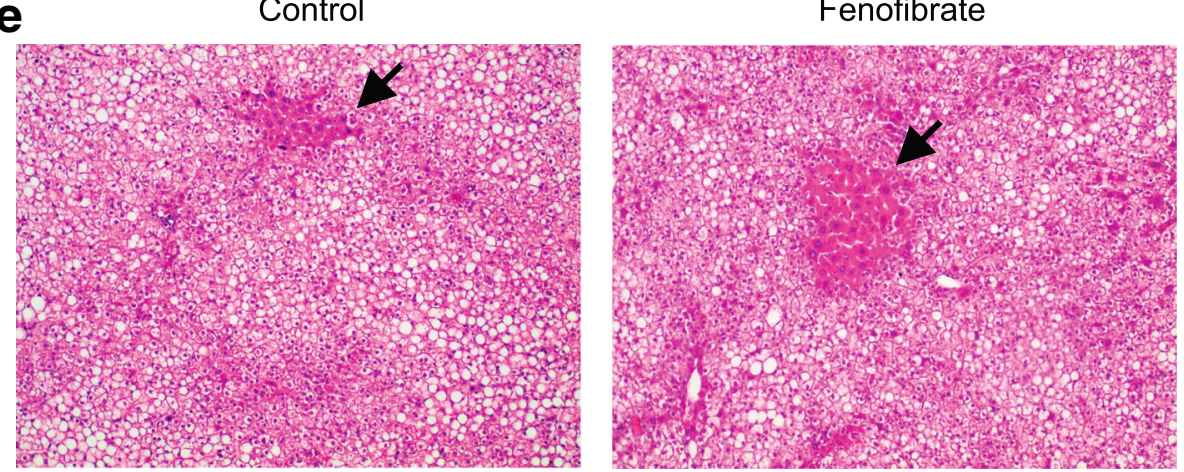

Fig. 2 Fenofibrate does not cause any changes in basic parameters in hepatocyte humanized mice. Chimeric mice containing hepatocyte humanized livers were treated with $300 \mathrm{mg} / \mathrm{kg}$ fenofibrate daily for 4 days. Control mice received vehicle only. a mRNA expression of PPARa in 15 human liver biopsies collected during bariatric surgery and in liver samples from 3 chimeric mice containing hepatocyte humanized livers. b Bodyweight and liver weight. c Blood human albumin concentration. d Plasma concentration of glucose, triglycerides and cholesterol. Error bars represent SEM. $N=3$ per group. e Histological examination of livers of chimeric mice containing hepatocyte humanized livers that received control or fenofibrate treatment. Hematoxilin and eosin staining was carried out according to standard protocols. Images are at $200 \times$ magnification. A section containing mouse hepatocytes is indicated (arrow). The mouse hepatocytes are present in clusters of non-steatotic cells, with the steatotic human hepatocytes taking up the remainder of the area. In addition, human hepatocytes show a light eosin staining while mouse hepatocytes are highly eosinophilic

Fenofibrate treatment significantly increased the expression of known PPAR $\alpha$ target genes in human and mouse hepatocytes (Fig. 3a). The overall inductions in gene expression were more pronounced in the mouse hepatocytes than the human hepatocytes. This was also observed for the genes that were measured in both human and mouse hepatocytes, including Angptl4, Vnn1, Pdk4 and Cpt1a (Fig. 3a). Consistent with the induction of ANGPTL4 mRNA, fenofibrate treatment also significantly increased levels of human ANGPTL4 in mouse plasma (Fig. 3b).

To study the difference in whole genome expression between the livers of control- and fenofibrate-treated mice, we performed transcriptomics analysis using the Affymetrix Human Gene 1.1 ST Array Plate. This approach allowed us to specifically determine the gene expression changes in the human hepatocytes and avoid potential interference of mouse hepatocytes.

Principle component analysis of the transcriptomics data showed that the livers of the fenofibrate-treated hepatocyte humanized mice clearly separated from the livers of the control-treated hepatocyte humanized mice (Fig. 4a). The liver samples from the fenofibrate-treated mice showed less variation than the liver samples from the control-treated mice. A dendogram confirmed the separate clustering of the two sets of samples (Fig. 4b). After filtering, a total of 282 genes was found to be significantly different between fenofibrate- and control-treated mice $(P<0.01)$, of which 159 genes were significantly higher and 123 genes were significantly 

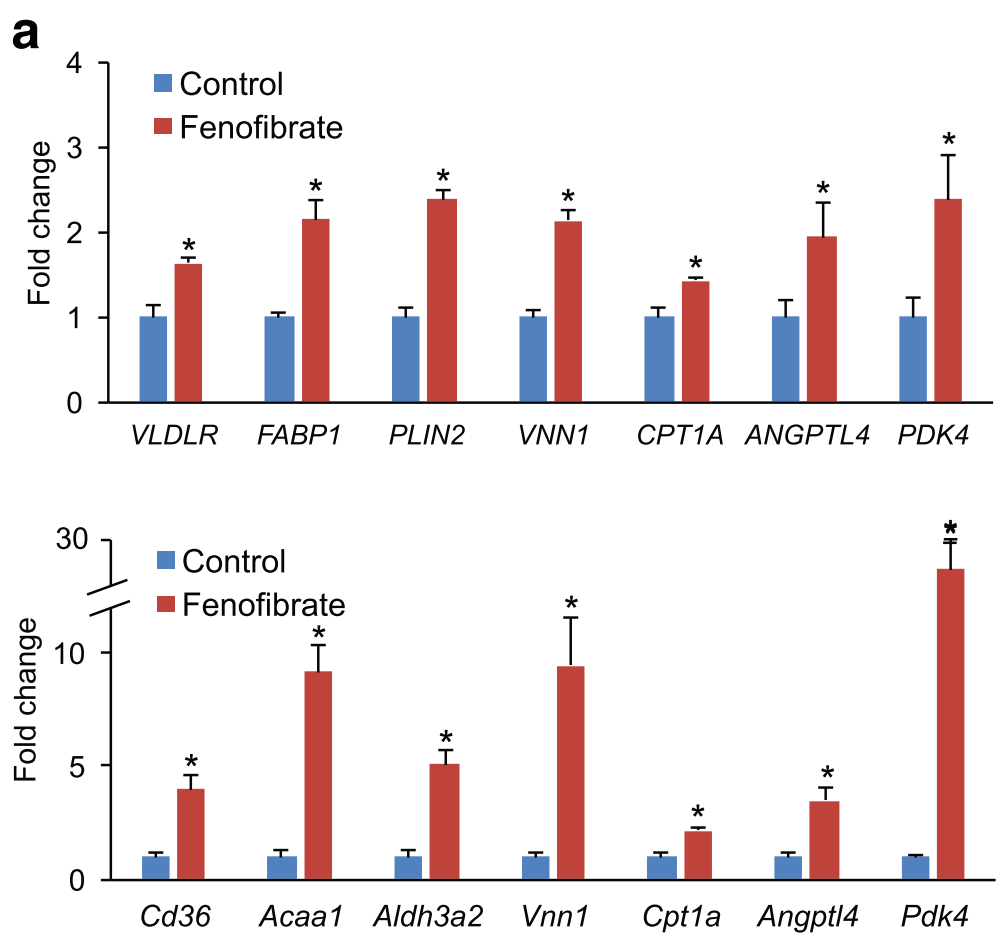

b

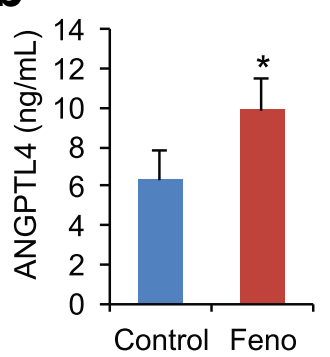

Fig. 3 Parallel induction of mouse and human PPARa target genes by fenofibrate in hepatocyte humanized livers. a qPCR was performed on CDNA generated from livers of control-treated and fenofibrate-treated mice containing hepatocyte humanized livers, using human primers (upper panel) or mouse primers (lower panel). b Concentration of ANGPTL4 in plasma of control-treated and fenofibrate-treated mice containing hepatocyte humanized livers, as determined by ELISA. Error bars represent SEM. $N=3$ per group. Asterisks indicate statistically significant difference between control and fenofibrate-treated mice according to Student's t-test with cut-off of $P<0.05$

lower in the fenofibrate-treated mice. The top 20 of most highly induced and repressed genes by fenofibrate is shown in Fig. 4c. The list of induced genes contains many established PPAR $\alpha$ targets connected to lipid metabolism, including $F A B P 1, H A D H B, H A D H A, V N N 1$, PLIN2, ACADVL and HMGCS2. The list of repressed genes is very diverse and does not reveal a common pathway. It includes cytokines (CCL16), coagulation factors (F5), structural proteins (ACTG1), transporters (SLC16A4/SLC6A12, and enzymes (DAK, PPIF). To gain further insight into the biological pathways induced or repressed by fenofibrate, genes that were significantly upregulated or downregulated by fenofibrate (IBMT $P$-value $<0.005)$ were further analyzed by Enrichr [31, 32]. The pathways induced by fenofibrate fell into two main categories: fatty acid metabolism and immunity/interferon signaling (Fig. 5). The pathways repressed by fenofibrate were mainly related to cell cycle, mitosis, and DNA synthesis, and to a lesser extent cytochrome P450-mediated biotransformation (Fig. 5).

Previously, we performed transcriptomics analysis on mouse livers harvested either $6 \mathrm{~h}$ after a single oral dose of fenofibrate (4 mg/mouse) or harvested from mice dosed daily with fenofibrate for 14 days by mixing it in the feed $(0.03 \mathrm{wt} / \mathrm{wt}$, equivalent to approximately $1 \mathrm{mg} /$ mouse/day). To compare the effect of fenofibrate in normal mouse liver and hepatocyte humanized liver, we performed a comparative analysis of the three transcriptomics datasets. Volcano plot showed that the two week dosing with fenofibrate in normal mice had a 

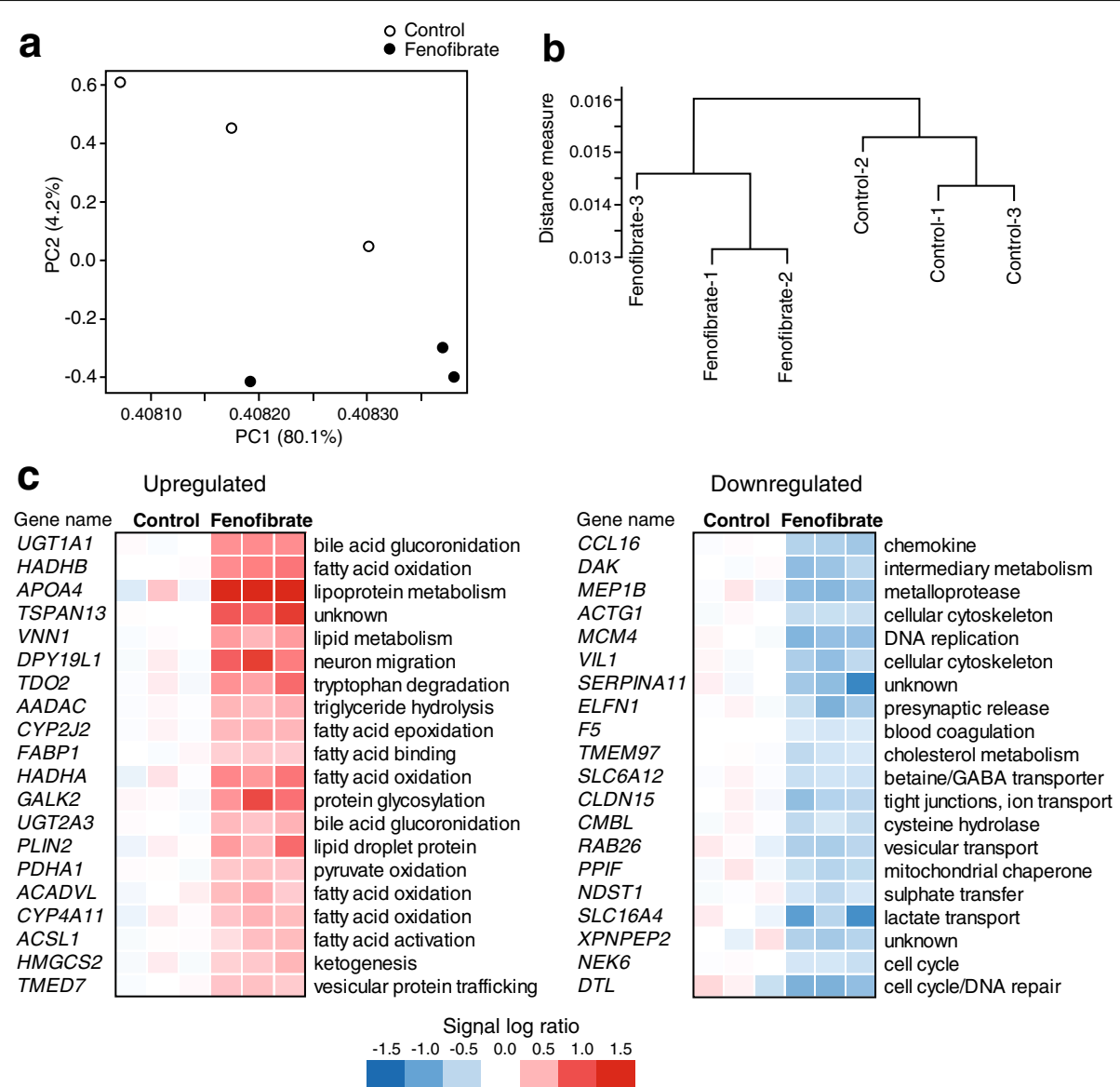

Fig. 4 Distinct clustering of livers of control-treated and fenofibrate-treated hepatocyte humanized mice. Transcriptomics was performed on livers of chimeric mice containing hepatocyte humanized livers. Mice were treated with $300 \mathrm{mg} / \mathrm{kg}$ fenofibrate daily for 4 days $(n=3)$ or vehicle (control, $n=3$ ). a Principle component analysis of transcriptomics data from the control- and fenofibrate-treated mice. The graph shows the clear separation of fenofibrate and control groups. $\mathbf{b}$ Hierarchical clustering of transcriptomics data from the control- and fenofibrate-treated mice. The dendogram reveals the distinct clustering and separation of the fenofibrate and control groups. c The top 20 most significantly upregulated and downregulated genes by fenofibrate were ranked according to statistical significance (IBMT $P$-value). The changes in gene expression are expressed relative to the mean of the control group as a signal log ratio

much bigger impact on liver gene expression as compared to the fenofibrate treatment in the hepatocyte humanized mice, which is not surprising given the longer duration of the treatment (Fig. 6). Surprisingly, the single treatment of normal mice with $4 \mathrm{mg}$ of fenofibrate also had a more pronounced effect on liver gene expression as compared to the 4-day treatment of the hepatocyte humanized mice with $\sim 6 \mathrm{mg}$ of fenofibrate per day (Fig. 6). These data suggest that in vivo, human liver cells are less sensitive to the effect of fenofibrate as compared to mouse liver cells, confirming the results of the qPCR on the hepatocyte humanized livers. Unfortunately, no transcriptomics dataset was available from normal mice treated with fenofibrate at the same dose and for the same duration as the hepatocyte humanized mice.

To further compare the effects of fenofibrate between normal mouse liver and hepatocyte humanized liver, we performed gene set enrichment analysis (GSEA). As expected, pathways covering PPAR $\alpha$ signaling and fatty acid oxidation featured prominently among the most significantly induced pathways in both normal mouse liver and hepatocyte humanized liver (Fig. 7a, red). The induction by fenofibrate of genes that are part of the geneset KEGG.FATTY.ACID.DEGRADATION is illustrated in Fig. 8, showing a consistent pattern of upregulation in hepatocyte humanized liver and normal mouse liver. Surprisingly, certain immune-related pathways such as interferon signaling were strongly upregulated in hepatocyte humanized liver, but were markedly downregulated in normal mouse liver (Fig. $7 \mathrm{a}$ and $\mathrm{b}$, green). The differential regulation of the geneset INTERFERON.ALPHA.BETA.SIGNALING by fenofibrate in hepatocyte humanized liver and normal mouse liver is visualized in Fig. 8.

With respect to down-regulated pathways, it was observed that many of the most significantly downregulated 


\section{KEGG}

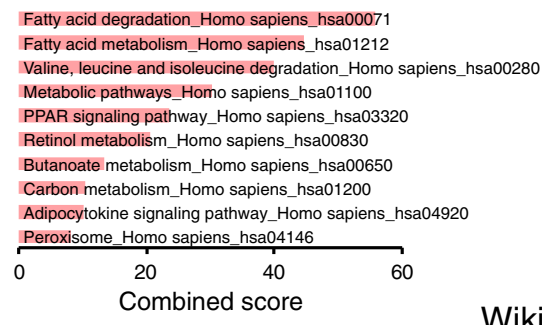

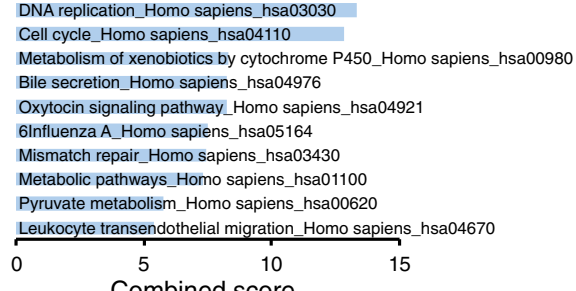

DNA Replication_Mus musculus_WP150 DNA Replication_Homo sapiens_WP466

Retinoblastoma (RB) in Cancer_Homo sapiens_WP2446 Metapathway biotransformation_Homo sapiens_WP702 G1 to S cell cycle control_Mus musculus_WP413 G1 to S cell cycle control_Homo sapiens_WP45 0.0005381 Cell Cycle_Homo sapiens_WP179 0.002522 Metapathway biotransformation_Mus musculus_WP1251 Oxidation by Cytochrome P450_Homo sapiens_WP43 Blood Clotting Cascade_Mus musculus WP460

$\begin{array}{llll}0 & 10 & 20 & 30\end{array}$

\section{Reactome}

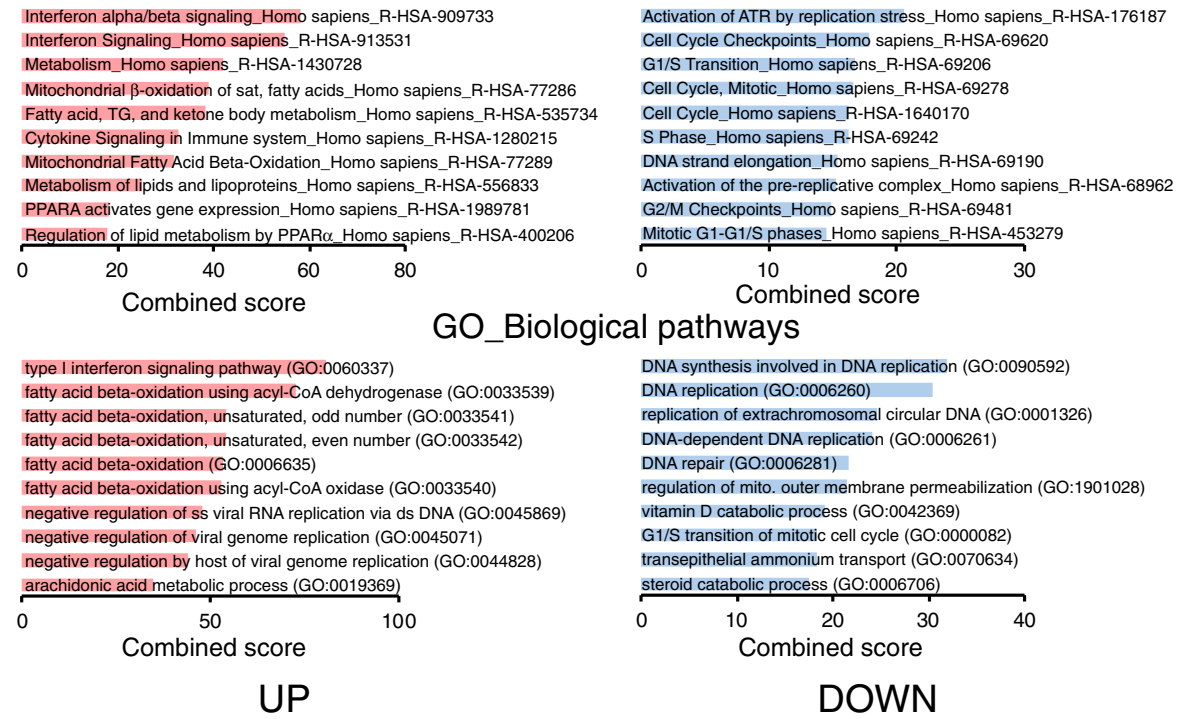

Fig. 5 Pathway analysis of differential gene expression between control-treated and fenofibrate-treated hepatocyte humanized mice. Transcriptomics was performed on livers of hepatocyte humanized mice treated with $300 \mathrm{mg} / \mathrm{kg}$ fenofibrate daily for 4 days ( $n=3$ ) or vehicle (control, $n=3$ ). Genes that were significantly upregulated (red bars) or downregulated (blue bars) by fenofibrate (IBMT $P$-value< 0.005$)$ were imported into the Enrichr tool (http://amp.pharm.mssm.edu/Enrichr/index.html) [31, 32]. The 10 pathways with the highest combined score are shown, in the following specific categories: KEGG, WikiPathways, Reactome, Gene ontology

pathways by fenofibrate in hepatocyte humanized liver were related to DNA synthesis (Fig. 7b, orange), which was not observed in normal mouse liver. Indeed, in normal mouse liver, fenofibrate significantly upregulated pathways related to cell cycle and DNA synthesis, although they were not in the top 20 pathways. The differential regulation of the geneset DNA.STRAND.ELONGATION by fenofibrate between hepatocyte humanized liver and normal mouse liver is visualized in Fig. 8. Interestingly, whereas certain genes such as RFC5 are consistently downregulated by fenofibrate in the two models, other genes such as MCM4 show opposite regulation by fenofibrate in hepatocyte humanized liver and normal mouse liver (Fig. 8).

The two most significantly repressed pathways by fenofibrate in normal mouse liver were related to complement and coagulation (Fig. 7b, violet). With the exception of F5 and perhaps F7, the suppressive effect of fenofibrate on complement and coagulation factors in normal liver was poorly reproduced in hepatocyte humanized livers (Fig. 8). Finally, pathways related to cholesterol biosynthesis were downregulated by fenofibrate 

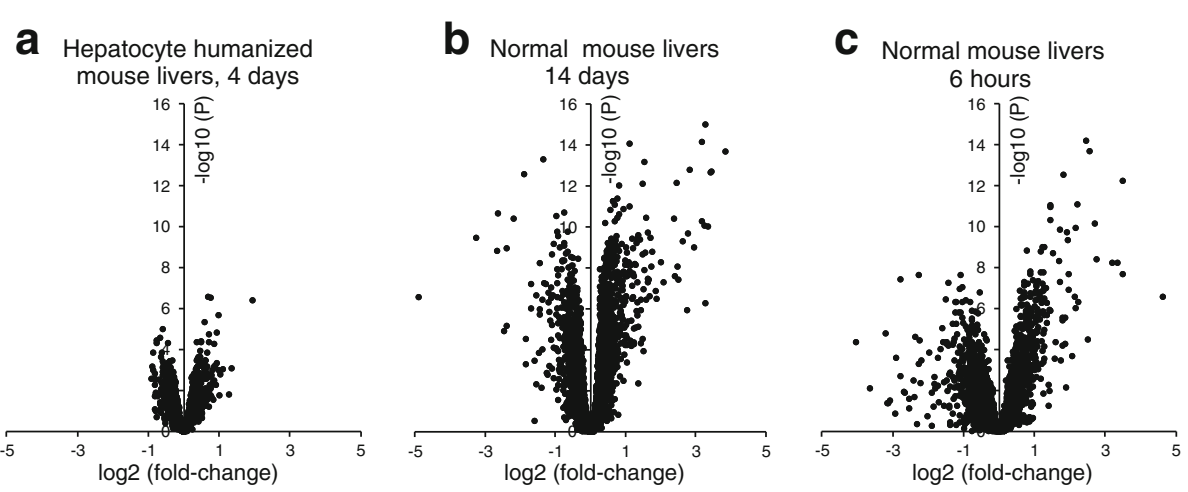

Fig. 6 Comparative analysis of the effect of fenofibrate in normal mouse liver and hepatocyte humanized liver. Volcano plots in which ${ }^{2}$ log(foldchange) is plotted against $-{ }^{10} \log (P$-value) for a Treatment of chimeric mice containing hepatocyte humanized livers with $300 \mathrm{mg} / \mathrm{kg}$ fenofibrate daily for 4 days as compared to control ( $n=3$ per group); b Treatment of wildtype mice with fenofibrate for 14 days via the feed (0.03 wt/wt, equivalent to approximately $1 \mathrm{mg} /$ mouse/day) as compared to control ( $n=8$ per group); $\mathbf{c}$ Treatment of wildtype mice with fenofibrate for $6 \mathrm{~h}$ via a single oral gavage of $4 \mathrm{mg} /$ mouse as compared to control ( $n=4-5$ per group)

in hepatocyte humanized liver, which also was not seen in normal mouse liver (Fig. 7b, grey). Overall, GSEA shows that the effects of fenofibrate in normal mouse liver and hepatocyte humanized liver are quite distinct, especially in relation to DNA synthesis pathways and interferon signaling pathways.

We previously studied the effect of PPAR $\alpha$ activation in human primary hepatocytes and human precision cut liver slices. The studies were not carried out with fenofibrate but with Wy14,643, another PPAR $\alpha$ agonist, precluding a whole genome comparison with the study in chimeric mice carrying hepatocyte humanized livers. Nevertheless, we took the top 40 most highly induced genes by fenofibrate in hepatocyte humanized livers and compared the fenofibrate-induced expression changes with the Wy-14,643-induced expression changes in human primary hepatocytes and human precision cut liver slices (Fig. 9). The most apparent difference was the regulation of several interferon-sensitive genes, including IFI6, IFITM1, PSMB9 and ISG15, which were upregulated by fenofibrate in the hepatocyte humanized mouse livers but downregulated by $\mathrm{Wy}-14,643$ in human primary hepatocytes and human precision cut liver slices. Other genes, nearly all representing genes involved in lipid metabolism, were consistently induced by PPAR $\alpha$ activation in the three model systems, with in general the highest fold-inductions observed in human primary hepatocytes.

\section{Discussion}

We previously showed that chimeric mice with hepatocyte humanized livers represent an appropriate model to investigate the pharmacological effects of fibrates on human liver [2]. By harbouring clusters of mouse and human hepatocytes, the hepatocyte humanized livers are also an ideal tool to study the parallel effects of a particular treatment on mouse and human hepatocytes. The main findings of the present study are: 1) The hepatocyte humanized livers recapitulate the principal effects of PPAR $\alpha$ activation on lipid metabolism revealed by other model systems of human liver. 2) The effects of PPAR $\alpha$ activation on gene expression in mice with hepatocyte humanized livers were modest compared to normal mouse liver, which is unlikely due to different treatment protocols. 3) Pathways connected to DNA synthesis were downregulated by fenofibrate in mice with hepatocyte humanized livers, yet are upregulated by fenofibrate in normal mouse livers. 4) Pathways connected to interferon/ cytokine signalling were upregulated by fenofibrate in mice with hepatocyte humanized livers, yet are downregulated by fenofibrate in normal mouse liver. 5) Chimeric mice with hepatocyte humanized livers can be used to study the effect of activation of PPAR $\alpha$ and other nuclear receptors on secretion of hepatokines into plasma.

Studies using human liver model systems, including HepG2 cells, human primary hepatocytes, human precision cut liver slices, and PPAR $\alpha$-humanized mice, have yielded detailed information about the effects of PPAR $\alpha$ activation on gene regulation in human liver. The results have been summarized in a recent review [19], highlighting the pivotal role of PPAR $\alpha$ in governing various metabolic processes and pathways in human liver. Our transcriptomics study in mice with hepatocyte humanized livers confirms the important role of PPAR $\alpha$ in regulating lipid metabolism in human liver. Many of the most highly induced genes are well-known targets of PPAR $\alpha$ involved in lipid metabolism, including FABP1, ANGPTL4, PDK4, HADHA, HADHA, PLIN2, and $A C A D V L$. The position of the fenofibrate-induced genes in cellular lipid metabolism is illustrated in Fig. 10. 

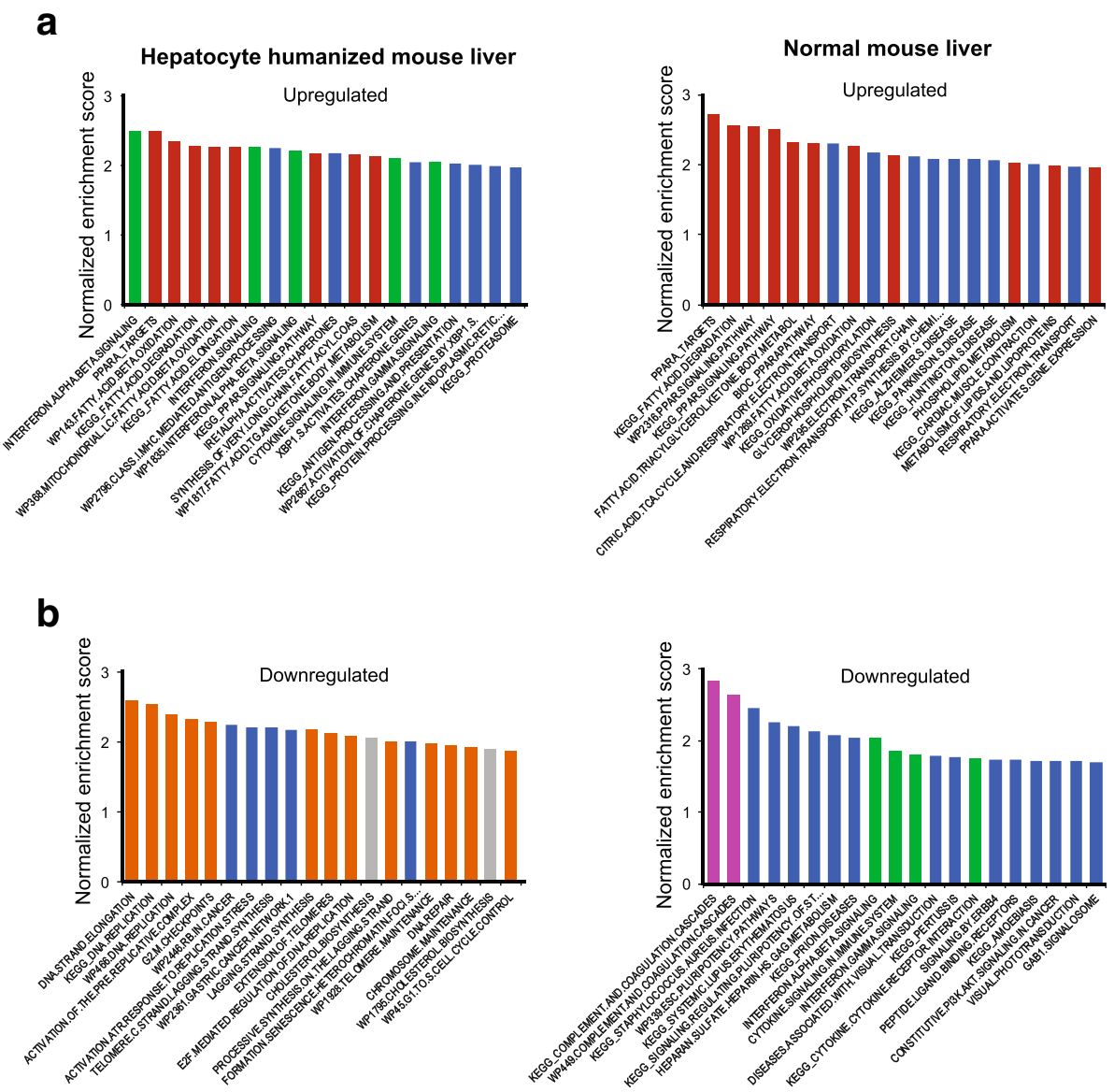

Fig. 7 Comparative pathway analysis of the effect of fenofibrate in normal mouse liver and hepatocyte humanized liver. Gene set enrichment analysis was performed on the effect of treatment of chimeric mice containing hepatocyte humanized livers with $300 \mathrm{mg} / \mathrm{kg}$ fenofibrate daily for 4 days ( $n=3$ per group), and on the effect of treatment of wildtype mice with fenofibrate for 14 days via the feed ( 0.03 wt/wt, equivalent to approximately $1 \mathrm{mg} / \mathrm{mouse} /$ day, $n=8$ per group). The top 20 most highly upregulated and downregulated genesets are shown, ranked according to normalized enrichment score. a The top 20 most highly upregulated genesets in hepatocyte humanized livers (left panel) and normal mouse livers (right panel). b The top 20 most highly downregulated genesets in hepatocyte humanized livers (left panel) and normal mouse livers (right panel). Genesets related to cytokine/interferon signalling are shown in green, genesets related to PPAR signalling and fatty acid oxidation are in red, genesets related to cholesterol synthesis are in grey, genesets related to DNA synthesis in orange, genesets related to complement and coagulation in violet

Chronic treatment of rodents with peroxisome proliferators causes hepato-carcinogenesis, while short-term treatment promotes hepatocyte and peroxisome proliferation $[15-17,33]$. These effects are dependent on induction of several genes involved in DNA synthesis, cell proliferation, and peroxisomal biogenesis and are known to be mediated by PPAR $\alpha$ [34]. The pro-carcinogenic effects of peroxisome proliferators led to concerns about their potential hepato-carcinogenicity in humans and triggered numerous studies aimed at investigating the effect of PPAR $\alpha$ in human liver model systems. Collectively, these studies have dispelled the notion that peroxisome proliferators are hepato-carcinogenic in humans and have also yielded a wealth of information about the role of PPAR $\alpha$ in human liver [19, 35]. In this study, we found that PPAR $\alpha$ activation in chimeric mice with hepatocyte humanized livers causes the downregulation of genes and pathways connected to DNA synthesis, further strengthening the notion that the effects of PPAR $\alpha$ activation on DNA synthesis, cell proliferation and hepato-carcinogenesis are distinct between mouse liver and human liver. The differential regulation is vividly illustrated by $M C M 4$, which was markedly downregulated by fenofibrate in hepatocyte humanized liver but strongly upregulated by fenofibrate in normal mouse liver. Our data thus further mitigate concerns about the hepato-carcinogenic effect of peroxisome proliferators in humans.

One of the major discrepancies between the effect of PPAR $\alpha$ activation in hepatocyte humanized liver and 


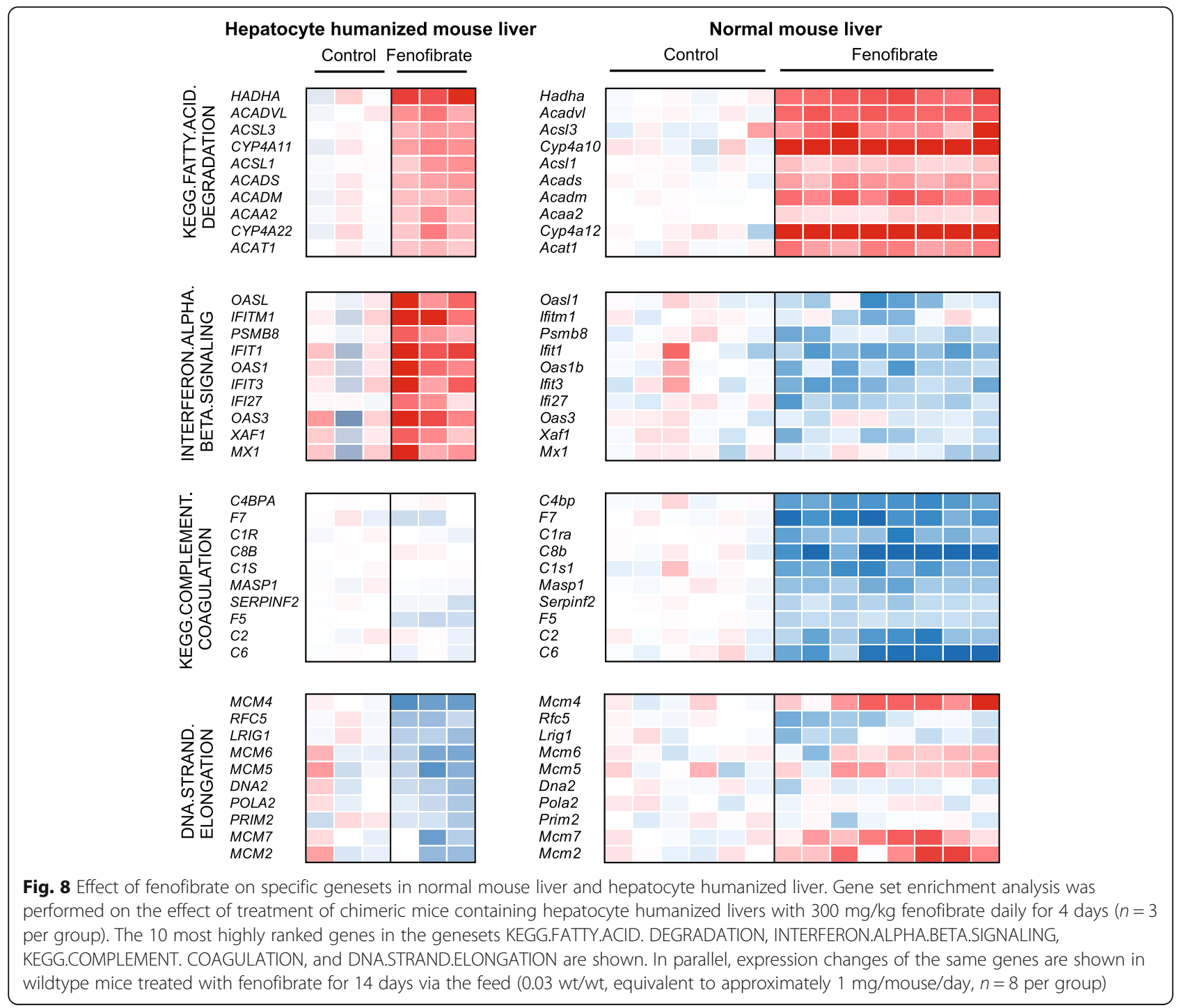

normal mouse liver is the regulation of immune-related pathways, especially interferon signaling. Whereas PPAR $\alpha$ activation causes the downregulation of interferon signaling in mouse liver, it led to upregulation of interferon signaling in hepatocyte humanized liver. Intriguingly, PPAR $\alpha$ activation caused the downregulation of interferon signaling in human precision cut liver slices [21]. Whether the upregulation of interferon signaling by PPAR $\alpha$ activation in hepatocyte humanized liver is an artefact of the interaction between human hepatocytes and mouse Kupffer cells, is related to the immune-deficiency in the SCID host mice, or in fact most accurately reflects the response to PPAR $\alpha$ activation in human liver remains to be established.

Another pathway that appears to be differentially regulated by PPAR $\alpha$ in hepatocyte humanized liver and normal mouse liver is complement and coagulation. The suppression of this pathway by fenofibrate and other PPAR $\alpha$ activators in normal mouse liver confirms previous analyses [36, 37], and was suggested to be an energy-saving mechanism [38]. With the exception of $F 5$ and possibly $F 7$, we did not observe any downregulation of coagulation genes by fenofibrate in hepatocyte humanized liver. With respect to the complement pathway, previously we demonstrated that mannose-binding lectin (MBL2) - the primary component of the lectin branch of the complement system-is a target of PPAR $\alpha$ and is markedly induced by PPAR $\alpha$ activation in primary hepatocytes and human liver slices [21, 39]. However, mRNA levels of $M B L 2$ and other complement-related genes were not altered by fenofibrate in hepatocyte humanized liver. In mouse liver, $M b l 2$ and other complement-related genes such as $C 8 b$ and $C 9$ are downregulated by PPAR $\alpha$ activation (Fig. 8) [36, 39]. These data indicate that 


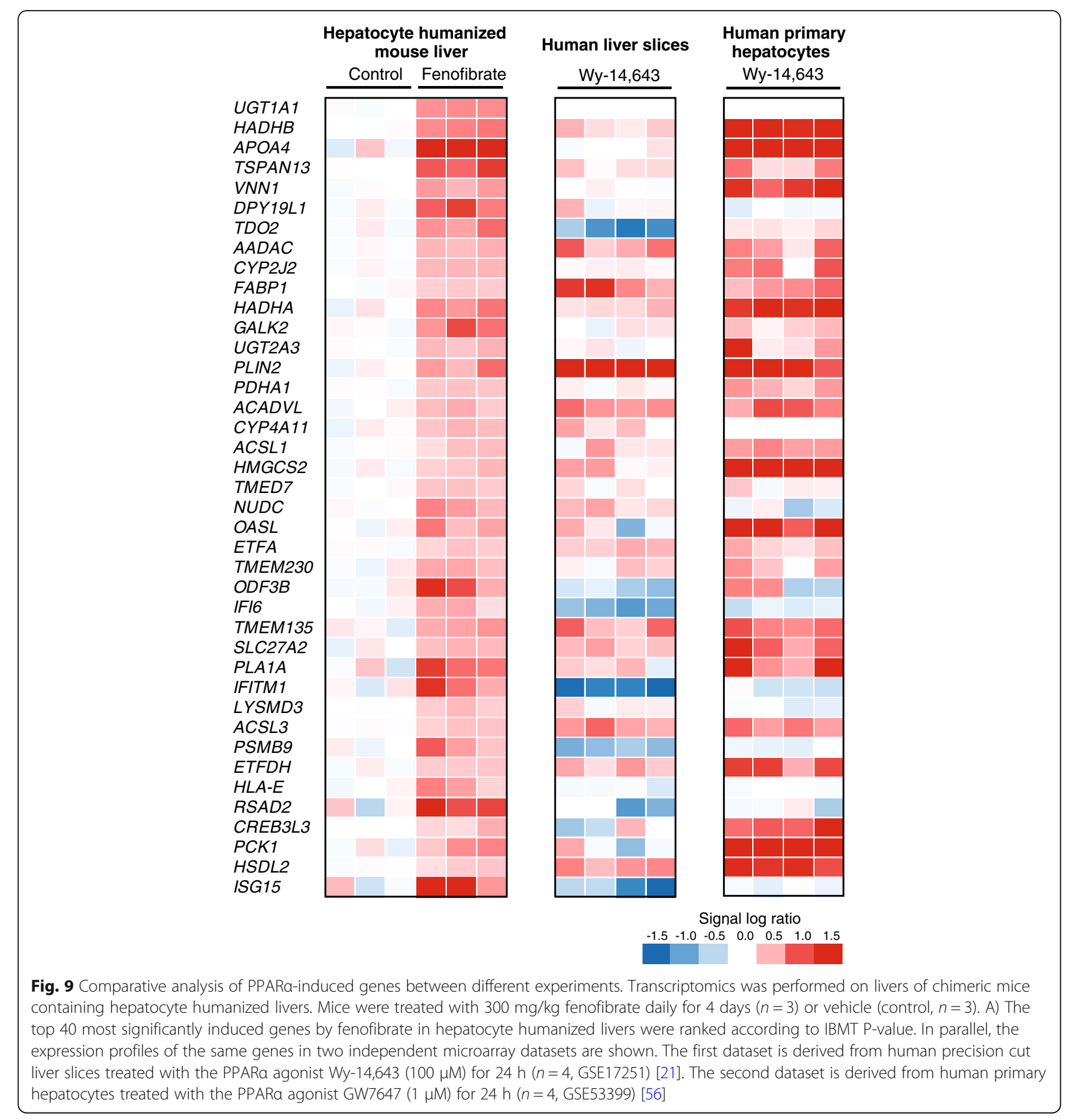

complement-related genes are differentially regulated by PPAR $\alpha$ in various model systems.

Activation of PPAR $\alpha$ alters the expression of a number of apolipoproteins, which may account for the plasma triglyceride-lowering and HDL-raising effects of PPAR $\alpha$ agonists in human patients [40]. For instance, fenofibrate was found to induce $A P O A 1$ expression in human primary hepatocytes and elevate plasma APOA1 levels in humans subjects $[41,42]$. Similarly, APOA5 was identified as a direct PPAR $\alpha$ target and was shown to be induced by PPAR $\alpha$ activators in human and cynomolgus hepatocytes [43, 44]. Consistent with these findings, administration of the PPAR $\alpha$ agonist LY570977 to cynomolgus monkeys increased serum APOA5 concentrations by 2-fold [45]. PPAR $\alpha$ activation has also been shown to regulate APOC3. Specifically, fenofibrate lowered $A P O C 3$ mRNA in human primary hepatocytes, concomitant with reduced secretion of APOC3 


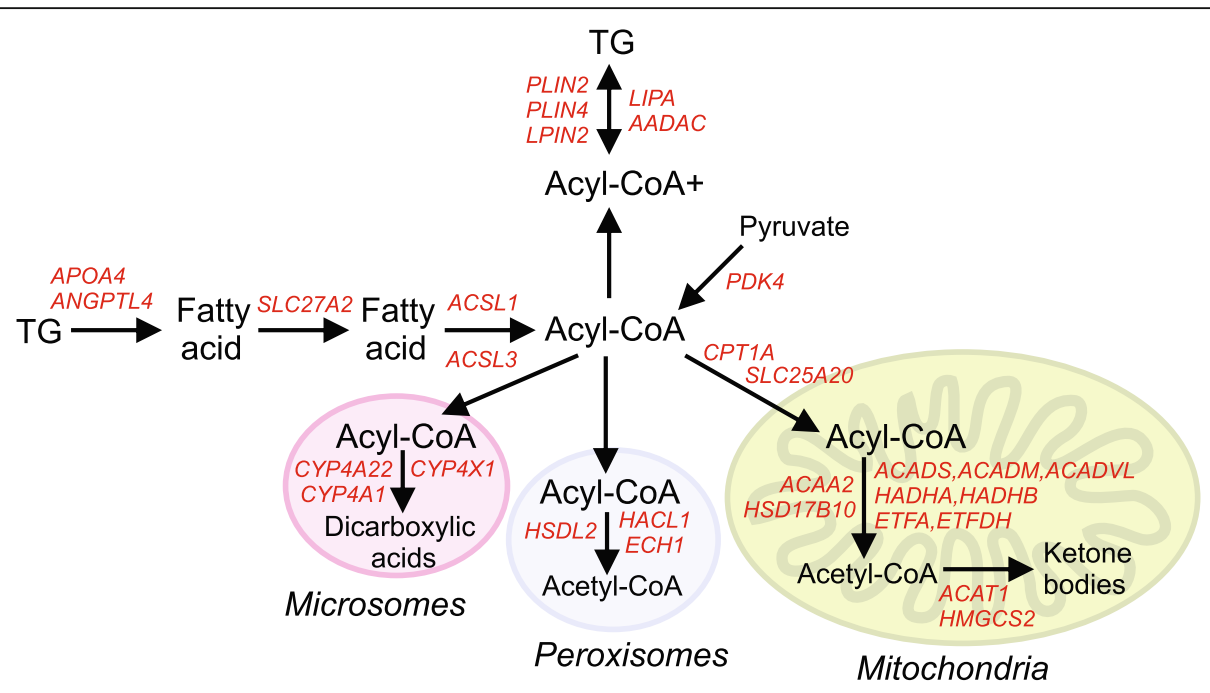

Fig. 10 Role of fenofibrate-induced genes in cellular lipid metabolism. Transcriptomics was performed on livers of chimeric mice containing hepatocyte humanized livers. Mice were treated with $300 \mathrm{mg} / \mathrm{kg}$ fenofibrate daily for 4 days $(n=3)$ or vehicle (control, $n=3$ ). Genes significantly induced by fenofibrate (IBMT P-value > 0.02) and with known roles in cellular lipid metabolism were selected. Their roles in specific pathways of cellular lipid metabolism is illustrated

in the culture medium [46]. Interestingly, in hepatocyte humanized mouse liver, fenofibrate treatment did not significantly change the expression of $A P O A 1$ and $A P O C 3$ mRNA, while it increased mRNA levels of $A P O A 4$ (fold-change $=3.9, P<0.0001$ ), and APOA5 (fold-change is 1.4, $P<0.05$ ). Our data, together with data from other human liver model systems, question the regulation of $A P O A 1$ and $A P O C 3$ mRNA by PPAR $\alpha$ activation in human liver.

The residual presence of mouse hepatocytes in the hepatocyte humanized mouse livers allowed for direct comparison of the effect of fenofibrate on human and mouse hepatocytes. The results show that the fold-changes in expression of the same genes are more pronounced in mouse as compared to human hepatocytes, verifying the notion that human hepatocytes are less sensitive to PPAR $\alpha$ activation.

Overall, it is evident that quantitative and qualitative differences in PPAR $\alpha$-mediated gene regulation exist between mouse and human hepatocytes. Unfortunately, this study provides minimal clues as to why the response to PPAR a activation is different in mouse and human hepatocytes. The lower fold-induction of genes related to lipid metabolism by fenofibrate in human versus mouse hepatocytes cannot be attributed to a lower expression of PPAR $\alpha$. Also, the relative binding affinity of fenofibrate for mPPAR $\alpha$ and hPPAR $\alpha$ appears to be similar [29]. Studies with humanized PPAR $\alpha$ mice suggest that differences in intrinsic properties of the mouse and human PPAR $\alpha$ protein are responsible for the qualitative differences in gene regulation between the two proteins. Indeed, mice expressing human PPAR $\alpha$ do not show hepatomegaly and induction of cell cycle control genes upon PPAR $\alpha$ activation [47]. By contrast, quantitative differences in gene regulation by PPAR $\alpha$ between human and mouse hepatocytes may be attributed to differences in the epigenetic landscape.

The use of chimeric mice with hepatocyte humanized livers in principle allows for study of the secretion of human liver proteins into the blood. Indeed, we were able to detect human ANGPTL4 in blood plasma of mice with hepatocyte humanized livers. Furthermore, following the induction of ANGPTL4 mRNA by PPAR $\alpha$, treatment of the mice with fenofibrate significantly increased plasma ANGPTL4 levels. These data are consistent with the increase in plasma ANGPTL4 levels in subjects treated with fenofibrate $[39,48]$. Intriguingly, the absolute level of ANGPTL4 in plasma of mice with hepatocyte humanized livers was similar to the levels observed in human subjects, suggesting that liver is the primary source of ANGPTL4 in plasma. Overall, these data suggest that chimeric mice with hepatocyte humanized livers are a suitable model to study the secretion of human liver proteins into the blood.

In our study, the livers of the hepatocyte humanized mice were very fatty, which was observed specifically in the liver sections populated by human hepatocytes. It has been demonstrated that the elevated lipid storage is likely due to a deficiency of the human growth hormone [30]. Whether the difference in lipid storage between mouse and human hepatocytes is in any way connected to differences in PPAR $\alpha$ expression or function remains unclear. The excess lipid storage in the hepatocyte humanized livers is a potential limitation for the study of lipid metabolism. 


\section{Conclusions}

In conclusion, using transcriptomics, we show that chimeric mice containing hepatocyte humanized livers are a highly valuable tool to study the in vivo function of PPAR $\alpha$ in human liver. The results confirm the major role of PPAR $\alpha$ in the regulation of hepatic lipid metabolism, yet also demonstrate the more modest effect of PPAR $\alpha$ activation on target gene induction in human hepatocytes as compared to mouse hepatocytes. The data suggest that PPAR $\alpha$ may have a suppressive effect on DNA synthesis in human liver, and a stimulatory effect on interferon/cytokine signalling.

\section{Methods}

\section{Animals}

The animal study was carried out in PXB mouse (Genotype: cDNA-uPA+/wt/SCID, uPA+/wt; B6;129SvEv-Plau, SCID; C.B-17/Icr-scid/scid Jcl) at PhoenixBio Co. Ltd. The mice were acquired from PhoenixBio Co. Ltd. A full description of the generation of these mice can be found elsewhere [49]. Briefly, cryopreserved human hepatocytes from a 2-year-old Hispanic girl were purchased from BD Biosciences (Woburn, MA, USA). After thawing, the hepatocytes were transplanted into hemizygous 2- to 4-week-old cDNA-uPA/SCID mice via the spleen under anesthesia. Six male mice between 12 and 18 weeks of age were used for the study.

Fenofibrate was dissolved in 0.5\% hydroxypropyl methylcellulose (Shinestu Kagaku Kogyo, Japan) and administered orally to the mice at a dose of $300 \mathrm{mg} / \mathrm{kg}$ once per day for 4 days with a disposable plastic sonde (Fuchigami Kikai Co., Kyoto, Japan). Three mice received fenofibrate and three mice received the control treatment with vehicle only.

The experiment was terminated $24 \mathrm{~h}$ after the final dosing with fenofibrate. Mice were anesthetized using isoflurane and a minimum of $300 \mu \mathrm{L}$ of blood was collected via cardiac puncture into sodium heparinized syringes. The mice were euthanized by exsanguination. Blood was used for measurement of human albumin or centrifuged to obtain plasma. Plasma was subsequently frozen at $-80{ }^{\circ} \mathrm{C}$. Liver tissue was collected and either frozen at $-80{ }^{\circ} \mathrm{C}$ or fixed in formaldehyde and further processed for histology. All experimental procedures were conducted in accordance with the guidelines provided by Proper Conduct of Animal Experiments (June 1, 2006; Science Council of Japan) and approved by the Animal Care and use Committee of PhoenixBio Co., Ltd. The animal handling guidelines that were followed in this study were based on the Act on Welfare and Management of Animals (Act No. 105 of October 1, 1973; hereinafter, the Act), The Standards and Norms for the Breeding and Housing of Laboratory Animals (Prime Minister's Notice \#6 of 1980; hereinafter, the Notice) and the Guidelines for Proper Conduct of Animal Experiments (June 1, 2006; Science Council of Japan).

\section{Plasma measurements}

Plasma concentrations of glucose (Sopachem, Ochten, the Netherlands), triglycerides, and cholesterol (Instruchemie, Delfzijl, the Netherlands) were determined following the manufacturers' instructions. The plasma concentration of ANGPTL4 was determined as previously described [48].

\section{RNA isolation and qPCR}

Total RNA of human and mouse tissue was isolated using TRIzol reagent (Invitrogen). RNA was reverse transcribed using the iScript cDNA Synthesis Kit (Bio-Rad Laboratories BV, Veenendaal, The Netherlands). Messenger RNA levels of selected genes were determined by reverse transcription quantitative PCR using SensiMix (Bioline; GC Biotech, Alphen aan den Rijn, The Netherlands) on a CFX384 real-time PCR detection system (Bio-Rad Laboratories, Veenendaal, the Netherlands). The housekeeping gene 36b4 was used for normalization. Sequences of the primers used are listed in Table 1. Mouse primers and human primers are specific for mouse and human, respectively. Primer pairs contain at least 4 mismatches with the other organism. Primer specificity was assessed using NCBI primer-BLAST.

\section{Microarray analysis}

For microarray hybridization, the isolated RNA was further purified using RNeasy Minikit columns (Qiagen). RNA concentrations were measured on a nanodrop ND-1000 UV-Vis spectrophotometer (Isogen, Maarssen, The Netherlands) and analyzed on an Agilent 2100 bioanalyzer (Agilent Technologies, Amsterdam, The Netherlands) with 6000 Nano Chips, according to the manufacturer's protocol. RNA was judged suitable for array hybridization only if samples exhibited intact bands corresponding to the $18 \mathrm{~S}$ and $28 \mathrm{~S}$ ribosomal RNA subunits, and displayed no chromosomal peaks or RNA degradation products.

Purified RNA (100 ng) was labeled with the Ambion WT expression kit (Invitrogen) and hybridized to Affymetrix Human Gene 1.1 ST arrays, provided in plate format (Affymetrix, Santa Clara, CA). Hybridization, washing and scanning of the array plates was performed on an Affymetrix GeneTitan instrument, according to the manufacturer's recommendations. Normalized expression estimates were obtained from the raw intensity values applying the robust multi-array analysis preprocessing algorithm available in the Bioconductor library 
Table 1 Sequences of primers used in qPCR analysis

\begin{tabular}{|c|c|c|}
\hline Name & Forward & Reverse \\
\hline $36 B 4 / 36 b 4$ & CGGGAAGGCTGTGGTGCTG & GTGAACACAAAGCCCACATTCC \\
\hline VNN1 & AGTGGCATCTATGCACCCAAT & GGAATCCAGTTGCGAGAGGA \\
\hline PPARA & CAGAACAAGGAGGCGGAGGTC & TTCAGGTCCAAGTTTGCGAAGC \\
\hline ANGPTL4 & CGTACCCTTCTCCACTTGGG & GCTCTTGGCGCAGTTCTTG \\
\hline CPT2 & GCATACGGGCAGATAAACCACAA & ACAGCATACCCAACACCAAAGC \\
\hline PDK4 & TGGAGCATTTCTCGCGCTAC & ACAGGCAATTCTTGTCGCAAA \\
\hline$V L D L R$ & GGTGAAAATGATTGTGACAGTGG & GTGAACTCGTCGGGACTACA \\
\hline PLIN2 & ATGGCAGAGAACGGTGTGAAG & CAACTGCAATTTGCGGCTC \\
\hline FABP1 & ATGAGTTTCTCCGGCAAGTACC & CTCTTCCGGCAGACCGATTG \\
\hline Cd36 & GAGCAACTGGTGGATGGTTT & GCAGAATCAAGGGAGAGCAC \\
\hline Acaal & AAGGCAGGTTGTCACGCTACT & CCTCAGTTCCCAGGGTATTCAAAG \\
\hline Aldh3a2 & CCTGAGCAAAAGTGAACTCAATG & GCTCCAATAATCAGTACGACTCC \\
\hline Ppara & TATTCGGCTGAAGCTGGTGTAC & CTGGCATTTGTTCCGGTTCT \\
\hline Angpt/4 & GTTGCAGACTCAGCTCAAGG & CCAAGAGGTCTATCTGGCTCTG \\
\hline Plin2 & CTTGTGTCCTCCGCTTATGTC & GCAGAGGTCACGGTCTTCAC \\
\hline$P d k 4$ & TCTACAAACTCTGACAGGGCTTT & CCGCTTAGTGAACACTCCTTC \\
\hline Vnn1 & СTTTCCTCGCGGCTGTTTAC & CCTCCAGGTATGGGTAGATCGT \\
\hline
\end{tabular}

AffyPLM with default settings [50, 51]. Probe sets were defined according to Dai et al. [52]. In this method probes are assigned to Entrez IDs as a unique gene identifier. In this study, probes were reorganized based on the Entrez Gene database, build 37, version 1 (remapped CDF v22), which excludes probes from analysis when they have more than 1 mismatch with the human genome, thereby largely assuring the human specificity of the analysis. The entire geneset was condensed by applying an Inter Quartile Range filter of 0.25 and by excluding genes with mean expression level below 20. The $P$ values were calculated using an Intensity-Based Moderated T-statistic (IBMT) [53]. Genes were defined as significantly changed when $P<0.01$. The microarray data were deposited at Gene Expression Omnibus (accession number GSE107041) and can be accessed via: https:// www.ncbi.nlm.nih.gov/geo/query/acc.cgi?acc=GSE107041.

Gene set enrichment analysis (GSEA) was used to identify genesets that were enriched among the upregulated or downregulated genes [54]. Genes were ranked based on the IBMT-statistic and subsequently analyzed for over- or underrepresentation in predefined genesets derived from Gene Ontology, KEGG, National Cancer Institute, PFAM, Biocarta, Reactome and WikiPathways pathway databases. Only genesets consisting of more than 15 and fewer than 500 genes were taken into account. Statistical significance of GSEA results was determined using 1000 permutations.

\section{Statistical analysis}

Data are presented as mean \pm SEM. Differences between the fenofibrate and control groups were analysed using two-tailed Student's t-test. $P<0.05$ was considered as statistically significant.

\section{Abbreviations}

GSEA: Gene Set Enrichment Analysis; PPAR: Peroxisome Proliferator Activated Receptor

\section{Acknowledgements}

The authors would like to thank Jenny Janssen and Karin Mudde for expert technical assistance.

\section{Funding}

This work was supported by grants from the Netherlands Organisation for Scientific Research (NWO-ALW, 2015/09169/ALW), the Netherlands Cardiovascular Research Initiative/Dutch Heart Foundation (CVON2014ENERGISE), and the Mexican National Council for Science and Technology (CONACYT, 455071).

\section{Availability of data and materials}

The microarray data were deposited at Gene Expression Omnibus (accession number GSE107041).

\section{Authors' contributions}

MR made substantial contributions to the conception and draft of the manuscript, performed the histological examination, GPCR, and plasma measurements. GS performed the animal study. GH analysed and interpreted data and edited the manuscript. YI performed the animal study and contributed to the writing of the manuscript. CT designed the animal study and contributed to the writing of the manuscript. SK conceived the idea, analysed and interpreted data, and drafted the manuscript. SK is responsible for the integrity of the work as a whole. All authors have read and approved the manuscript. 


\section{Ethics approval and consent to participate}

All experimental procedures were conducted in accordance with the guidelines provided by Proper Conduct of Animal Experiments (June 1, 2006; Science Council of Japan) and approved by the Animal Care and use Committee of PhoenixBio Co., Ltd.

\section{Competing interests}

The authors have nothing to disclose. Go Sugahara, Yuji Ishida and Chise Tateno are employees of PhoenixBio Co., Ltd.

\section{Publisher's Note}

Springer Nature remains neutral with regard to jurisdictional claims in published maps and institutional affiliations.

\begin{abstract}
Author details
'Nutrition, Metabolism and Genomics group, Division of Human Nutrition and Health, Wageningen University, Stippeneng 4, 6708, WE, Wageningen, The Netherlands. ${ }^{2}$ Research and Development Department, PhoenixBio, Co, Ltd, 3-4-1 Kagamiyama, Higashi-, Hiroshima, Japan. ${ }^{3}$ Liver Research Project Center, Hiroshima University, 1-2-3, Kasumi, Minami-ku, Hiroshima, Japan.
\end{abstract}

\section{Received: 30 November 2017 Accepted: 29 May 2018}

Published online: 07 June 2018

\section{References}

1. Gross B, Pawlak M, Lefebvre P, Staels B. PPARs in obesity-induced T2DM, dyslipidaemia and NAFLD. Nat Rev Endocrinol. 2017;13(1):36-49.

2. Tateno C, Yamamoto T, Utoh R, Yamasaki C, Ishida Y, Myoken Y, Oofusa K, Okada M, Tsutsui N, Yoshizato K. Chimeric mice with hepatocyte-humanized liver as an appropriate model to study human peroxisome proliferatoractivated receptor-alpha. Toxicol Pathol. 2015;43(2):233-48.

3. Varga T, Czimmerer Z, Nagy L. PPARs are a unique set of fatty acid regulated transcription factors controlling both lipid metabolism and inflammation. Biochim Biophys Acta. 2011;1812(8):1007-22.

4. Gearing KL, Gottlicher M, Teboul M, Widmark E, Gustafsson JA. Interaction of the peroxisome-proliferator-activated receptor and retinoid $X$ receptor. Proc Natl Acad Sci U S A. 1993;90(4):1440-4.

5. Issemann I, Prince RA, Tugwood JD, Green S. The retinoid X receptor enhances the function of the peroxisome proliferator activated receptor. Biochimie. 1993;75(3-4):251-6.

6. Keller H, Dreyer C, Medin J, Mahfoudi A, Ozato K, Wahli W. Fatty acids and retinoids control lipid metabolism through activation of peroxisome proliferator-activated receptor-retinoid $X$ receptor heterodimers. Proc Natl Acad Sci U S A. 1993;90(6):2160-4.

7. Georgiadi A, Kersten S. Mechanisms of gene regulation by fatty acids. Adv Nutr. 2012;3(2):127-34

8. Bookout AL, Jeong Y, Downes M, Yu RT, Evans RM, Mangelsdorf DJ. Anatomical profiling of nuclear receptor expression reveals a hierarchical transcriptional network. Cell. 2006;126(4):789-99.

9. Escher P, Braissant O, Basu-Modak S, Michalik L, Wahli W, Desvergne B. Rat PPARs: quantitative analysis in adult rat tissues and regulation in fasting and refeeding. Endocrinology. 2001;142(10):4195-202.

10. Kersten S, Seydoux J, Peters JM, Gonzalez FJ, Desvergne B, Wahli W. Peroxisome proliferator-activated receptor alpha mediates the adaptive response to fasting. J Clin Invest. 1999;103(11):1489-98.

11. Leone TC, Weinheimer CJ, Kelly DP. A critical role for the peroxisome proliferator-activated receptor alpha (PPARalpha) in the cellular fasting response: the PPARalpha-null mouse as a model of fatty acid oxidation disorders. Proc Natl Acad Sci U S A. 1999:96(13):7473-8.

12. Regnier M, Polizzi A, Lippi Y, Fouche E, Michel G, Lukowicz C, Smati S, Marrot A, Lasserre F, Naylies C, et al. Insights into the role of hepatocyte PPARalpha activity in response to fasting. Mol Cell Endocrinol. 2017;

13. Kersten S. Integrated physiology and systems biology of PPARalpha. Molecular metabolism. 2014;3(4):354-71.

14. Issemann I, Green S. Activation of a member of the steroid hormone receptor superfamily by peroxisome proliferators. Nature. 1990;347(6294):645-50.

15. Lee SS, Pineau T, Drago J, Lee EJ, Owens JW, Kroetz DL, Fernandez-Salguero PM, Westphal H, Gonzalez FJ. Targeted disruption of the alpha isoform of the peroxisome proliferator-activated receptor gene in mice results in abolishment of the pleiotropic effects of peroxisome proliferators. Mol Cell Biol. 1995;15(6):3012-22.
16. Reddy JK, Lalwai ND. Carcinogenesis by hepatic peroxisome proliferators: evaluation of the risk of hypolipidemic drugs and industrial plasticizers to humans. Crit Rev Toxicol. 1983;12(1):1-58.

17. Corton JC, Lapinskas PJ, Gonzalez FJ. Central role of PPARalpha in the mechanism of action of hepatocarcinogenic peroxisome proliferators. Mutat Res. 2000:448(2):139-51.

18. Gonzalez FJ. The peroxisome proliferator-activated receptor alpha (PPARalpha): role in hepatocarcinogenesis. Mol Cell Endocrinol. 2002;193(1-2):71-9.

19. Kersten S, Stienstra R. The role and regulation of the peroxisome proliferator activated receptor alpha in human liver. Biochimie. 2017;136:75-84.

20. Rakhshandehroo M, Hooiveld G, Muller M, Kersten S. Comparative analysis of gene regulation by the transcription factor PPARalpha between mouse and human. PLoS One. 2009;4(8):e6796.

21. Janssen AW, Betzel B, Stoopen G, Berends FJ, Janssen IM, Peijnenburg AA, Kersten $\mathrm{S}$. The impact of PPARalpha activation on whole genome gene expression in human precision cut liver slices. BMC Genomics. 2015;16(1):760.

22. Mukherjee R, Jow L, Noonan D, McDonnell DP. Human and rat peroxisome proliferator activated receptors (PPARs) demonstrate similar tissue distribution but different responsiveness to PPAR activators. J Steroid Biochem Mol Biol. 1994;51(3-4):157-66.

23. van der Meer DL, Degenhardt T, Vaisanen S, de Groot PJ, Heinaniemi M, de Vries SC, Muller M, Carlberg C, Kersten S. Profiling of promoter occupancy by PPARalpha in human hepatoma cells via ChIP-chip analysis. Nucleic Acids Res. 2010;38(9):2839-50.

24. Kandel BA, Thomas M, Winter S, Damm G, Seehofer D, Burk O, Schwab M, Zanger UM. Genomewide comparison of the inducible transcriptomes of nuclear receptors CAR, PXR and PPARalpha in primary human hepatocytes. Biochim Biophys Acta. 2016;1859(9):1218-27.

25. Morimura K, Cheung C, Ward JM, Reddy JK, Gonzalez FJ. Differential susceptibility of mice humanized for peroxisome proliferator-activated receptor alpha to $\mathbf{W y}$-14,643-induced liver tumorigenesis. Carcinogenesis. 2006;27(5):1074-80.

26. Yang Q, Nagano T, Shah Y, Cheung C, Ito S, Gonzalez FJ. The PPAR alphahumanized mouse: a model to investigate species differences in liver toxicity mediated by PPAR alpha. Toxicol Sci. 2008;101(1):132-9.

27. Mercer DF, Schiller DE, Elliott JF, Douglas DN, Hao C, Rinfret A, Addison WR, Fischer KP, Churchill TA, Lakey JR, et al. Hepatitis C virus replication in mice with chimeric human livers. Nat Med. 2001:7(8):927-33.

28. Tateno C, Yoshizane Y, Saito N, Kataoka M, Utoh R, Yamasaki C, Tachibana A, Soeno $\mathrm{Y}$, Asahina $\mathrm{K}$, Hino $\mathrm{H}$, et al. Near completely humanized liver in mice shows human-type metabolic responses to drugs. Am J Pathol. 2004;165(3):901-12.

29. Willson TM, Brown PJ, Sternbach DD, Henke BR. The PPARs: from orphan receptors to drug discovery. J Med Chem. 2000;43(4):527-50.

30. Tateno C, Kataoka M, Utoh R, Tachibana A, Itamoto T, Asahara T, Miya F, Tsunoda T, Yoshizato K. Growth hormone-dependent pathogenesis of human hepatic steatosis in a novel mouse model bearing a human hepatocyte-repopulated liver. Endocrinology. 2011;152(4):1479-91.

31. Chen EY, Tan CM, Kou Y, Duan Q, Wang Z, Meirelles GV, Clark NR, Ma'ayan A. Enrichr: interactive and collaborative HTML5 gene list enrichment analysis tool. BMC Bioinformatics. 2013;14:128

32. Kuleshov MV, Jones MR, Rouillard AD, Fernandez NF, Duan Q, Wang Z, Koplev S, Jenkins SL, Jagodnik KM, Lachmann A, et al. Enrichr: a comprehensive gene set enrichment analysis web server 2016 update. Nucleic Acids Res. 2016;44(W1):W90-97.

33. Gonzalez FJ, Peters JM, Cattley RC. Mechanism of action of the nongenotoxic peroxisome proliferators: role of the peroxisome proliferatoractivator receptor alpha. J Natl Cancer Inst. 1998;90(22):1702-9.

34. Peters JM, Aoyama T, Cattley RC, Nobumitsu U, Hashimoto T, Gonzalez FJ. Role of peroxisome proliferator-activated receptor alpha in altered cell cycle regulation in mouse liver. Carcinogenesis JID - 8008055. 1998;19(11):1989-94.

35. Corton JC, Cunningham ML, Hummer BT, Lau C, Meek B, Peters JM, Popp JA, Rhomberg L, Seed J, Klaunig JE. Mode of action framework analysis for receptor-mediated toxicity: the peroxisome proliferator-activated receptor alpha (PPARalpha) as a case study. Crit Rev Toxicol. 2014;44(1):1-49.

36. Lu Y, Boekschoten MV, Wopereis S, Muller M, Kersten S. Comparative transcriptomic and metabolomic analysis of fenofibrate and fish oil treatments in mice. Physiol Genomics. 2011;43(23):1307-18.

37. Szalowska E, Tesfay HA, van Hijum SA, Kersten S. Transcriptomic signatures of peroxisome proliferator-activated receptor alpha (PPARalpha) in different mouse liver models identify novel aspects of its biology. BMC Genomics. 2014;15:1106. 
38. Kim KH, Moore DD. Regulation of liver energy balance by the nuclear receptors Farnesoid $\mathrm{X}$ receptor and peroxisome proliferator activated receptor alpha. Dig Dis. 2017;35(3):203-9.

39. Rakhshandehroo M, Stienstra R, de Wit NJ, Bragt MC, Haluzik M, Mensink RP, Muller M, Kersten S. Plasma mannose-binding lectin is stimulated by PPARalpha in humans. Am J Physiol Endocrinol Metab. 2012;302(5):E595-602.

40. Duval C, Muller M, Kersten S. PPARalpha and dyslipidemia. Biochim Biophys Acta. 2007;1771(8):961-71.

41. Berthou L, Duverger N, Emmanuel F, Langouet S, Auwerx J, Guillouzo A, Fruchart JC, Rubin E, Denefle P, Staels B, et al. Opposite regulation of human versus mouse apolipoprotein $\mathrm{A}$-l by fibrates in human apolipoprotein A-I transgenic mice. J Clin Invest. 1996;97(11):2408-16.

42. Duez H, Lefebvre B, Poulain P, Torra IP, Percevault F, Luc G, Peters JM Gonzalez FJ, Gineste R, Helleboid S, et al. Regulation of human apoA-l by gemfibrozil and fenofibrate through selective peroxisome proliferatoractivated receptor alpha modulation. Arterioscler Thromb Vasc Biol. 2005; 25(3):585-91.

43. Prieur X, Coste $\mathrm{H}$, Rodriguez JC. The human apolipoprotein AV gene is regulated by peroxisome proliferator-activated receptor-alpha and contains a novel farnesoid X-activated receptor response element. J Biol Chem. 2003; 278(28):25468-80.

44. Vu-Dac N, Gervois P, Jakel H, Nowak M, Bauge E, Dehondt H, Staels B, Pennacchio LA, Rubin EM, Fruchart-Najib J, et al. Apolipoprotein A5, a crucial determinant of plasma triglyceride levels, is highly responsive to peroxisome proliferator-activated receptor alpha activators. J Biol Chem. 2003:278(20):17982-5.

45. Schultze AE, Alborn WE, Newton RK, Konrad RJ. Administration of a PPARalpha agonist increases serum apolipoprotein A-V levels and the apolipoprotein A-V/apolipoprotein C-III ratio. J Lipid Res. 2005;46(8):1591-5.

46. Staels B, Vu-Dac N, Kosykh VA, Saladin R, Fruchart JC, Dallongeville J, Auwerx J. Fibrates downregulate apolipoprotein C-III expression independent of induction of peroxisomal acyl coenzyme a oxidase. A potential mechanism for the hypolipidemic action of fibrates. J Clin Invest. 1995;95(2):705-12.

47. Cheung C, Akiyama TE, Ward JM, Nicol CJ, Feigenbaum L, Vinson C, Gonzalez FJ. Diminished hepatocellular proliferation in mice humanized for the nuclear receptor peroxisome proliferator-activated receptor alpha. Cancer Res. 2004;64(11):3849-54.

48. Kersten S, Lichtenstein L, Steenbergen E, Mudde K, Hendriks HF, Hesselink MK, Schrauwen P, Muller M. Caloric restriction and exercise increase plasma ANGPTL4 levels in humans via elevated free fatty acids. Arterioscler Thromb Vasc Biol. 2009;29(6):969-74.

49. Tateno C, Kawase Y, Tobita Y, Hamamura S, Ohshita H, Yokomichi H, Sanada H, Kakuni M, Shiota A, Kojima Y, et al. Generation of novel chimeric mice with humanized livers by using hemizygous CDNA-UPA/SCID mice. PLoS One. 2015;10(11):e0142145.

50. Bolstad BM, Irizarry RA, Astrand M, Speed TP. A comparison of normalization methods for high density oligonucleotide array data based on variance and bias. Bioinformatics. 2003;19(2):185-93.

51. Irizarry RA, Bolstad BM, Collin F, Cope LM, Hobbs B, Speed TP. Summaries of Affymetrix GeneChip probe level data. Nucleic Acids Res. 2003;31(4):e15.

52. Dai M, Wang P, Boyd AD, Kostov G, Athey B, Jones EG, Bunney WE, Myers RM, Speed TP, Akil H, et al. Evolving gene/transcript definitions significantly alter the interpretation of GeneChip data. Nucleic Acids Res. 2005;33(20):e175.

53. Sartor MA, Tomlinson CR, Wesselkamper SC, Sivaganesan S, Leikauf GD, Medvedovic M. Intensity-based hierarchical Bayes method improves testing for differentially expressed genes in microarray experiments. BMC Bioinformatics. 2006; 7:538.

54. Subramanian A, Tamayo P, Mootha VK, Mukherjee S, Ebert BL, Gillette MA Paulovich A, Pomeroy SL, Golub TR, Lander ES, et al. Gene set enrichment analysis: a knowledge-based approach for interpreting genome-wide expression profiles. Proc Natl Acad Sci U S A. 2005;102(43):15545-50.

55. Ahrens M, Ammerpohl O, von Schonfels W, Kolarova J, Bens S, Itzel T, Teufel A, Herrmann A, Brosch M, Hinrichsen $\mathrm{H}$, et al. DNA methylation analysis in nonalcoholic fatty liver disease suggests distinct disease-specific and remodeling signatures after bariatric surgery. Cell Metab. 2013;18(2):296-302.

56. McMullen PD, Bhattacharya S, Woods CG, Sun B, Yarborough K, Ross SM, Miller ME, McBride MT, Lecluyse EL, Clewell RA, et al. A map of the PPARalpha transcription regulatory network for primary human hepatocytes Chem Biol Interact. 2013;209C:14-24.

\section{Ready to submit your research? Choose BMC and benefit from:}

- fast, convenient online submission

- thorough peer review by experienced researchers in your field

- rapid publication on acceptance

- support for research data, including large and complex data types

- gold Open Access which fosters wider collaboration and increased citations

- maximum visibility for your research: over $100 \mathrm{M}$ website views per year

At BMC, research is always in progress.

Learn more biomedcentral.com/submissions 